\title{
National memory institutions' social media policies and risk management: a content analysis
}

National MIs SM policies and risk management

\author{
Chern Li Liew \\ School of Information Management, Victoria University of Wellington, \\ Wellington, New Zealand
}

Received 19 September 2020 Revised 8 January 2021 Accepted 28 May 2021

\begin{abstract}
Purpose - Among the current discourses around social media risk management (SMRM) is whether institutions perceive social media (SM) as more of an opportunity to be embraced and regulated, or a risk to be avoided or mitigated, how this is reflected in their policies and how institutional stance reflects their regulation and management of SM use and practices. There is currently no scholarly literature that addresses these for the memory sector where SM use has proliferated. This research aims to address this gap by putting a focus on national memory institutions (MIs), whose strategies and operations are often governed by a public/civic mandate.

Design/methodology/approach - This research involves a comprehensive literature review and a content analysis. The review includes studies that have analysed institutional SM policies in other sectors. The review informs our content analysis both in terms of approaches and in terms of identifying areas for comparisons. Following an initial scoping review and a close inspection, a sample of eight policies of national MIs were included in the content analysis.

Findings - The content analysis led to the identification of 8 core themes and 36 sub-themes. The main themes are concerned with account management, audience management, rules for use, protecting institutional interests, legal considerations, the purpose of the policy, nature of postings and referencing information. Also emerged from the findings are a few gaps that we expect will provide a platform for further discourses with regard to the potentially complex role SM policies have in MIs and the broader cultural heritage sector in relation to their public/civic mandates.

Originality/value - This is the first close SM policy analysis for the memory sector focusing on national MIs. This research contributes insights into how national-level MIs tend to frame the opportunities and the risk of SM use, the ways in which they govern SM usage and their different approaches to SMRM. The findings have implications for SM policy development and implementations, and further iterations of SM policies in the memory sector.
\end{abstract}

Peer review - The peer review history for this article is available at: https://publons.com/publon/10.1108/OIR09-2020-0421

Keywords Content analysis, Policy analysis, Cultural heritage institutions, National memory institutions, Social media policies, Social media risk management

Paper type Research paper

\section{Introduction}

Memory institutions (MIs), including libraries, archives, museums and public galleries play an important function of curating, preserving and communicating collective memory (Manžuch, 2009). Like other institutions and organisations, MIs have been using social media (SM) platforms to extend and innovate the services they provide. This use brings with it the benefits for outreach and promotion of institutional goals, collections and services (Williamson et al, 2015) and audience engagement (Parilla and Ferriter, 2016; Duff et al., 2013; Heyliger et al.,2013). However, there are also risks that come with SM, including institutional reputation risks, and legal and compliance issues (Walsh and O'Connor, 2019; Di Gangi et al, 2018). The literature around social media risk management (SMRM) has increased, as governments, institutions and corporations of all kinds grapple to balance the risks and benefits of SM use.

This research was funded by Victoria University of Wellington WSBG Grant 3969-221773.

Online Information Review (C) Emerald Publishing Limited DOI 10.1108/OIR-09-2020-0421 
While there is a body of literature on SM use in MIs and documented examples of poor SMRM in MIs, scholarly literature on SMRM with regard to the memory sector remains scant. Liverant (2017) provides a rare example of an ill-managed SM risk and the failings of ad hoc SM policy through case study of a museum exhibition that was the subject of controversy originating on SM. The controversy related to an exhibition hosted by the Museum of Fine Arts (MFA), Boston in 2015, titled "Claude Monet: Flirting with the Exotic". It was intended to be a representation of a "19th century European perspective of Oriental otherness" (p. 63). One aspect of the exhibition was that visitors could try on and pose for photos in a replica of the kimono depicted in Monet's famous Orientalist painting, La Japonaise. The MFA promoted the exhibition and related events on its Facebook page in a manner that many people felt was culturally insensitive. The exhibition had been transplanted to the cultural context of the USA from Japan, whereas Japanese visitors had the cultural context to interpret the layered meanings of the exhibition, for most Americans, this context was lost. Critics of the exhibition and MFA's communication and promotion of it through SM felt it reinforced the misunderstanding of Japanese Americans and Japanese culture in a country with a long history of discrimination against Japanese people and Asian migrants in general. This case study demonstrates that there is a risk of reputational damage when MIs mismanage SM risk.

This paper presents a literature review and the findings of a content analysis of SM policies of MIs. This is the first close SM policy analysis for the memory sector, with a focus on national MIs. This research contributes insights into how national-level MIs tend to frame the opportunities and risks of SM use, the ways in which they govern SM usage and their different approaches to SMRM. The research contributes to discourses on SM policy. The findings have implications for policy development and implementations, and further iterations of SM policies in MIs. Also emerged from the findings are a few gaps that we expect will provide a platform for further discourses with regard to the potentially complex role SM policies have in MIs and in the broader cultural heritage sector, in relation to their public/civic mandates.

\section{Related works}

\subsection{Social media: use and potential risks}

Mathur (2019) explores the growing risk associated with corporations hoarding vast amounts of user information that could become the target of hacks or leaks. She states that perceived cybersecurity risk harms retailer reputation but that a proactive SM marketing projecting integrity and authenticity can lessen this negative effect and improve overall reputation (p. 218). Miller (2018) discusses the potential risks and benefits of SM use within the nursing profession. She emphasises that for nurses, their professional and personal use of SM must take strict patient privacy laws into account to protect patient privacy. Magoi et al. (2019) examined the use of SM in academic libraries in developing countries in Asia and Africa. Their study did not specifically pertain to SMRM but they reinforced that institutions like libraries must ensure they did not associate SMRM with a general avoidance of using SM, and to remember the potential benefits that could be gained from its effective use. The "boons" they identified pertained to open up the possibility for communication between the library, its staff, its users and its potential users, in addition to staff development. Most of the "banes" they identified have more to do with a lack of resourcing and inadequate infrastructure. Nevertheless, they briefly mentioned the privacy risks and potential abuse experienced by staff and how challenging it could be to control or moderate distressing behaviour (p. 382).

Comrie et al. (2019) examined the use of Twitter by official organisations, particularly those in the public health sector in Nova Scotia and Scotland. Their findings with regard to SMRM revealed that reputational risk was a common concern. The health professionals interviewed in this study discussed the way in which Twitter could become an important source of information regarding public health risks and if they were slow to make an announcement on SM, or used other mediums that the public and the media were unaware of, 
that could undermine their credibility. Being slow in making a statement or appearing to be using irrelevant platforms could lead to a lack of trust in public health organisations. Proactive use of Twitter was identified as a being of significant in cultivating trust and managing reputational risk.

\subsection{Social media strategies, frameworks and policies}

Faber et al. (2020) and Köseoğlu and Tuncer (2016) studied the development and implementation of SM policies in the context of local governments. Their discussion did not go in-depth into a comparative analysis of SMRM between the private and public sectors. However, they made suggestions with regard to this. Köseoğlu and Tuncer (2016) suggested that local governments could draw on policies in the private sector (p. 31) and emphasised that there was no one-size-fits-all approach to developing SM policies. While guidelines from national governments and the public sector are useful for local governments, they must also consider their own particular mandates and goals in concert with their residents' expectations. Faber et al. (2020) meanwhile implied that although SM policy were driven by the socio-economic characteristics and citizen preferences within municipalities to some extent, the political dimension must not be overlooked.

While development of SMRM in the public and private sectors, broadly defined, has useful lessons for MIs, individual institutions and the sector in general, will need to consider the contexts within which they function, including their institutional mandates, SM goals and strategies and the audience and communities they wish to inform and engage.

Haynes (2016) identified a number of risks associated with organisational SM use. Broadly, these related to employee misconduct such as time wasting, committing libel, reputational damage, copyright concerns and data insecurity that could lead to information breach or fraud. Haynes also identified "Loss of opportunity (by not using social media)" as a risk alongside these other risks (p. 2). In suggesting that not using SM is in and of itself a possible opportunity loss, and therefore a risk, Haynes embeds the potential benefits of SM within the framework of risk. This suggestion stands as a counter-point to a common discourse in other literature, which is that organisations are risk-averse to the point of stifling innovation or effective use of SM (Klang and Nolin, 2011; Fudurić and Mandelli, 2017; ColeMiller et al., 2016; Ryan, 2016). For example, Fudurić and Mandelli (2017) suggested that the utility of SM policy was its potential to "guide" rather than "prevent" staff from using SM , and that SM use should be encouraged, with clear parameters and expectations as to the nature of that use. In locating not using SM within the risk matrix of SM use, there lies some potential to conceptualise the risk avoidance alongside responsible and meaningful SM use.

Sherer et al. (2019) articulated some of the potential legal and reputational risks of using SM. They noted the ubiquity of SM in marketing and recommended that any strategy and policy used to govern its use should "start with considerations of what is already happening with the organization's presence, its brand and its customers and employees" (p. 2). Regarding risk, they propose that SM sites "have risk built into them as a design component" (p. 2). They argued that employees in particular were at risk of divulging sensitive information including internal documents and emails, proprietary information or other confidential data via SM. Organisational SM policies should, therefore, be broad enough to cover a wide range of potentially compromising activities or actions. They emphasised employee use of SM as the greatest risk on a consistent basis, while addressing external threats as less common but potentially, more serious. Specifically, they discussed the legal implications of defamatory or personally threatening SM posts and advised that SM policies forbid this kind of behaviour from employees. Their paper is interesting in the sense that they looked at these risks through a legal perspective, albeit not in great depth.

Fletcher and Lee (2012) reported that only 35\% of the American museums they surveyed had set goals or objectives for their SM use. A more recent survey by Fleming and Damala
National MIs SM policies and risk

management

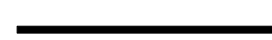




\section{OIR}

\section{Figure 1.}

The SCOPE

framework for social media communication
(2016) found that only $40 \%$ of cultural institutions they surveyed had a SM strategy document and $49 \%$ had a SM policy. This could be a cause for concern. Previous research has established that SM policies are a key component of SMRM (Demek et al., 2018; Di Gangi et al., 2018).

Lessard et al. (2017) proposed a framework for SM communication in the museum context (Figure 1), noting the substantial potential that SM held for museums to communicate their collections to their audience and go further to engage in dialogue with the audience. They discussed the risks and challenges of SM use in museums, including the need to divert staff attention away from research and curation in order to create content for SM and the potential for the public to react negatively to a SM campaign. On the latter, they emphasised the importance of the "evaluation" component-emphasising that any negative responses should be assessed and the resulting lessons be incorporated into future SM campaigns. Although Lessard et al. (2017) used natural history collections as a case study, the SCOPE framework represents an attempt to create a SM policy framework that originates from within the community of professionals working in the memory sector. As an attempt at developing best practice for SM, it suggests that risks and benefits can be minimised and maximised, respectively, through deliberate planning. Appropriate SM policies that guide decisions and practices should be part of this planning.

\subsection{Content analyses of social media policies}

Given the importance of SM policy documents as a part of the governance framework when managing SM risk, knowing what these policies contain can provide insights into the risk framing and risk mitigation strategies by the institutions concerned. There is a body of literature that applies the content analysis method to examine SM policies in a variety of sectors, including the education sector, governments, not-for-profits, media organisations and the private sector. As they represent the findings from a variety of sectors, they provide a

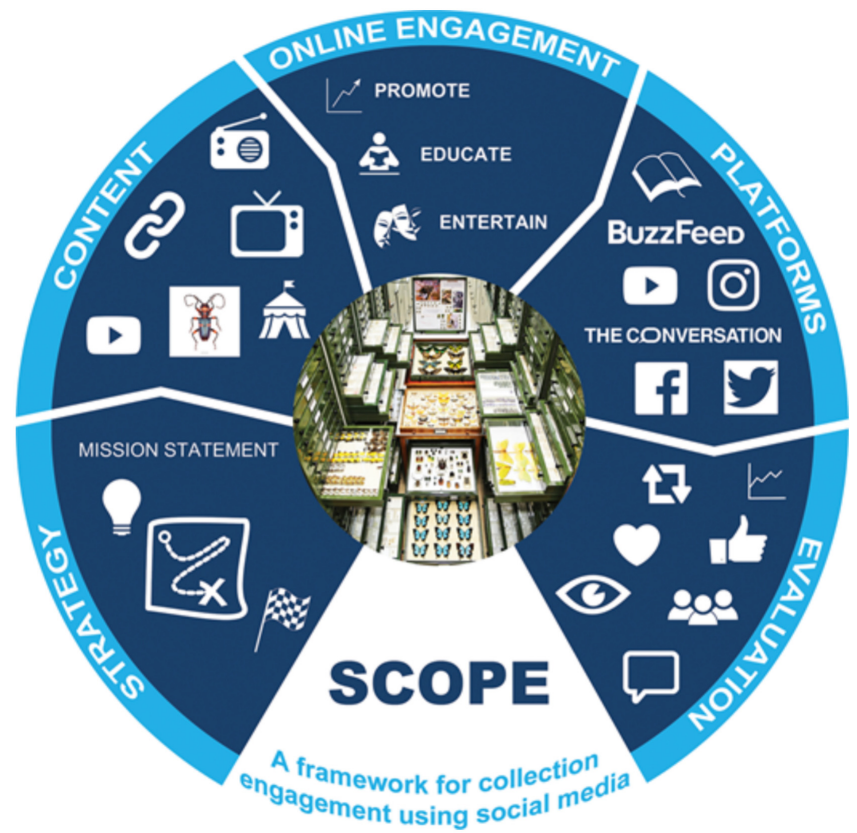

Source(s): Lessard et al., 2017 
snapshot of what SM policies tend to contain at a generic level and highlight the areas of concerns and discussion that are specific to the sector from which they are drawn. They serve as examples of approaches and provide points of comparison to the SM policies of MIs in our study.

Rodesiler (2017) conducted a content analysis of SM policies in 30 schools in a particular district in the Midwest of the USA. Common themes included delineating, though often not clearly, the boundaries between teachers' personal and educational use of SM and the paramount need to protect the privacy of students. Policies often opened with the exact same definition of SM, which reflected the use of a generic template as a starting point for the policies. McNeill (2012) looked at SM policies in higher education (HE) institutions. He argues that these policies were largely driven by the "marketisation" of HE. The need to build a cohesive institutional brand for marketing purposes in a competitive $\mathrm{HE}$ environment necessitates a cohesive SM policy. McNeill argued that this not only mitigated reputational risk by monitoring and regulating SM use but also helped to construct and/or reinforce a particular institution's brand. This aligns with Cadell's (2013) point, that SM policies should not only protect organisations, but also "enforce brands and inspire confidence for those using social media within an organisation ... a good social media policy, therefore, does not only protect but also provides an explanation as to why the institution or organisation uses social media in the first place" (p. 6).

Pomerantz et al. (2015) conducted a comprehensive study of American HE institutions. Of the 4,581 institutions in their sample, only about $18 \%$ had SM policies. They stated that SM policies in universities must be attuned to issues of academic freedom and in the USA, First Amendment rights. In this sense, institutions must balance this imperative with policies that protect their reputation and branding. This can be perceived as a tension between traditional notions of what universities should be and the "marketisation" of HE identified by McNeill (2012). This tension appears to play out in the SM policies of HE institutions.

Pasquini and Evangelopoulos (2017) examined 250 SM policies from HE institutions around the world. They teased out 26 "universal topics" that describe the kinds of topics that SM policies tended to contain in HE. Within these topics, perhaps unsurprisingly, they noted some notable geographic differences, suggesting that $\mathrm{HE}$ institutions in different countries had different priorities for their SM policies. The authors suggested that their study provided a reference point for developing SM policies, as well as establishing a "sociotechnical stewardship framework for strategic technology planning" (p. 234).

Turning to SM policies in governments, a study by Hrdinová et al. (2010) identified 8 "essential elements" of SM policies in government from an analysis of $26 \mathrm{SM}$ policies from government departments and interviews with government employees. The elements that they identified were employee access, account management, acceptable use, employee conduct, content, security, legal issues and citizen conduct. The authors made suggestions on how to set up SM policy for governments.

Klang and Nolin (2011) conducted an analysis of SM policies in 26 Swedish municipalities. They found that in the main, these policies attempted to map onto existing regulatory procedures and frameworks, thereby limiting novel or experimental use. The authors felt that this limited the potential for SM to be an avenue for participation between citizens and their governments and that this framing tended to fixate on SM as a problem to be regulated, rather than an opportunity to be embraced-in other words, the policies reflected a risk-averse approach to SM. Like McNeill (2012) and Cadell (2013), they also identified some cases in which the SM policy acted as part of a marketing strategy, in part existing to boost the "brand" goals of a particular municipality.

In a more recent study, Bennett and Manoharan (2017) analysed SM policies for municipalities in the USA. They saw SM policies as an important and natural part of the adoption of SM for governments that aim to engage with and even collaborate with citizens in 
order to create more democratic processes. However, according to a previous research (Bertot et al., 2012), the regulatory framework for SM in the USA at a federal level is a "patchwork" of different laws, regulations and executive orders. Their intention was to see how SM was regulated at the municipal level. They included 156 cities, of which just 31 had a SM policy. They found that while many policies included statements that indicated that SM should further the strategic vision of the city, very few described two-way engagement with citizens as an important reason to use SM. They concluded that while many municipal governments were using SM, few had policies to guide this use and the potential benefits for collaboration with citizens had not been reflected.

Cole-Miller et al. (2016) looked at the SM policies and directives of the Department of Defense (DOD) in the USA. Their study incorporated risk as a central theme, asking whether the DOD SM policies incorporate risk. As is supported by previous research, they found that in general the DOD takes a risk-averse approach. The policies identified risks and had a focus on "What Not to Post". The authors argue that this highlighted the fact that "organizations tend to attempt to provide guidelines that avoid consequences, rather than encouraging the responsible use" (p. 98).

Ryan (2016) conducted an analysis of the SM policies created by professionals nursing bodies. She concluded that in general, they lacked specificity to the profession of nursing. Most offered generic advice regarding confidentiality. She found that these policies generally did not effectively highlight the potential positive uses of SM for the nursing profession. In this regard, Ryan's findings are similar to those of Klang and Nolin (2011). She suggested that professional nursing bodies were still "negotiating the novelty of, conflicting views about, and limited evidence on, nursing and social media" (p. 33).

There have also been some analyses of SM policies in the mainstream media sector. Lee (2016) suggested that in the 12 industry-leading newsrooms she studied, news organisations were generally "concerned about the current social media environment rather than excited about it" (p. 121). They were particularly concerned with reputational risk and inadvertently spreading false information on SM. This reflects similar findings elsewhere in the SMRM literature. She also believed that their policies did not reflect the increasingly digital norms in journalistic, particularly with regard to direct online interactions between journalists and consumers of news. Duffy and Knight (2019) also examined SM policies in news organisations, including how they addressed journalistic norms such as objectivity, which their analysis revealed were reaffirmed in SM policies with statements to the effect that while SM might be a new platform for journalism, long-standing journalistic values must still be observed on SM. They too noted the potential reputational or commercial damage that could arise from journalists' SM use.

Fudurić and Mandelli (2017) presented one of the few studies that compared SM policies between corporate and non-profit organisations. They noted both the lack of research into SM policies in general and that few studies had sought to compare and contrast SM management in different types of organisations. They provided evidence that generally, SM policies in different sectors differed in noteworthy ways that reflected the different contexts in which they operated.

What these content analyses of SM policies reveals is that most, if not all policies reflect the particular institutional contexts, which in turn sit within broader professional fields, in which they function. Nevertheless, there are common features. For instance, the need to manage reputation, respect copyright, ensure privacy is protected and avoid libel on SM. Procedural matters such as advice on the nature and tone of content posted to SM or the systems in place to create and manage accounts are also common. This indicates that regardless of sector of origin, there are common features in SM policies. However, these studies also draw inferences about particular concerns within industries based on their analysis of SM documents. The particular emphases placed on common features, the 
presence of considerations unique to particular sectors, and the framing of risks and benefits around contextual discourses can reveal particular risks or specific benefits that SM poses. In secondary schools for example, particular attention was paid to the importance of protecting students' privacy (Rodesiler, 2017). Meanwhile, in one of the rare studies that compare policies from different sectors, Fuduric and Mandeli (2017) show that SM policies of corporations differ from those of public/not-for-profit institutions. Collectively, these content analyses show that SM policies signal the priorities and concerns of different sectors.

The literature also illustrates how the content in SM policies can be placed into conversation with contemporary discourses within the sector these policies are derived from. In academia for instance, academic freedom must be upheld in the SM sphere. In governments, SM policies that do not put an emphasis on interactions with citizens may be inadvertently inhibiting this potentially powerful use of SM. Similar suggestions had been made regarding the SM policies in mainstream newsrooms. Ryan (2016) argued that SM policies in professional nursing bodies could be more specific to the potential issues that could arise in the profession.

There are previous studies that evaluate how many MIs tend to have SM policies and whether institutions find these policies useful (Fletcher and Lee, 2012; Fleming and Damala, 2016). However, the kind of content analysis of SM policies as reviewed above is not evident for MIs. Cadell (2013) examined the experiences of professionals using SM policies in MIs in Queensland, Australia. Employees in three MIs supported the idea that SM policies were useful in providing a framework for staff's SM use. However, this study did not include a content analysis of the policies concerned.

What then, are the particular considerations SM policies of MIs around the world reveal? What are the reasons behind the development and implementation of these policies? What do they encompass? Do they differ from the characteristics of SM policies, guidelines and codes of conduct in other sectors? What features do they include which are specific to MIs? How do they reflect the purview, mandate and requirements of a particular MI, for instance, a library or a museum tasked with caretaking a nation's collective memory and cultural heritage knowledge? Might specific practical and theoretical concerns of libraries, archives, museums and public galleries be reflected in their SM policies? Are current discourses and developments within the memory and cultural heritage sector with regard to their SM use notably reflected or absent in their SM policies, for instance, regarding audience interaction (Lessard et al., 2017) and participatory heritage (Liew and Cheetham, 2016)?

\section{Research design}

Among the current discourses around SMRM is whether institutions perceive SM as more of an opportunity to be embraced and regulated, or a risk to be avoided and mitigated, how this is reflected in their policies and how institutional stance reflects their regulation and management of SM use and practices. There is currently no scholarly literature that addresses these for the memory sector where SM use has proliferated. This research addresses this gap by putting a focus on national MIs, whose strategies and operations are often governed by a public/civic mandate.

The rationale for focussing on national MIs was to enhance the internal validity of the comparisons made. While specific national contexts inevitably has an influence on the goals of their national institutions, it is reasonable to assume that at a broad level, national MIs exist to record, curate, preserve and communicate the collective memories and cultural heritage knowledge of a particular country. These institutions share a common mandate, if not necessarily similar in scope and nature of their collections. This mandate carries with it a weighty responsibility, often framed by legislation and government oversight. It is likely that these institutions would have similar concerns regarding their SM presence, and that their 
SM policies could provide a place where these are manifested. We are interested in examining policies targeting both internal staff and the public using these MIs, and the potentially complex role SM policies have in these institutions, in relation to their public/civic mandates.

A scoping review conducted in October-December 2019 led to the identification of 41 national MIs with evident SM use, as evidenced in their SM platforms. These included institutions in Australia, Canada, Denmark, Finland, Iceland, Ireland, New Zealand, Norway, Singapore, South Africa, Sweden, the United Kingdom and the USA. Of these institutions, five had SM policies for staff publicly available online, four were in English and one was in Icelandic. The latter was excluded from the study sample. In total, 12 institutions had policies that outlined very brief guidelines for user (the public) conduct and there was no evidence of guidelines for internal SM practices. As such, these were also excluded.

During January-February 2020, we contacted the 36 institutions with no publiclyavailable policy asking if a policy could be made available for the research. Regrettably, the response rate was low. About $55 \%$ of the MIs contacted (20 institutions) did not respond. Of those that did respond, four provided their policies for our study. Four expressed interest in the research but noted that their policies were not in English language; two responded that they could not release their policies as they were confidential internal documents; two responded that their institutions had no SM policy; and two other responded that their policy was currently under review and would not be finalised until after this research had concluded.

This led to a final sample of eight SM policies for our close content analysis. One from Australia, one from Finland, one from New Zealand, two from the United Kingdom and three from the USA (Table 1). A point worth noting is that the National Library of New Zealand (NLNZ) policy is a general SM policy document for the NZ Department of Internal Affairs, within which the NLNZ sits. This makes it slightly different to the other policies in our sample. With no details available on the development of the policy, it is impossible to ascertain to what extent the NLNZ had input into its formulation. Nevertheless, it is the document NLNZ uses to guide their SM use, and as such, is included in the analysis.

Only policies available in the public domain were included in our analysis. No research ethics application was required at our institution.

\subsection{Delimitations and limitations}

Institutional SM policies can change considerably as experience and expertise with SM use develop and, as institutions respond to changes and demands in their operative environments. Our final analyses were largely conducted during March-April 2020. As such, it provides a snapshot that does not reflect changes made to the policies after this timeframe.

We also acknowledge the similar nature of the institutions from which the sample policies are drawn from. While there is a reasonable coverage of different types of MIs and five countries are represented in the sample, encompassing four national libraries, two national museums and two national archives, with our small sample, there should be some caution in assuming broad generalisability of findings across other national-level MIs and MIs in general. Nevertheless, other content analyses of SM policies were based on relatively small samples and provided confidence that worthwhile results could be attained from small samples for studies of this kind. Lee (2016) had a sample size of 12 while Duffy and Knight (2019) had a sample of 17 , for example, in their studies related to the media sector. Furthermore, by including other content analyses of SM policy documents in our literature review, we were able to compare against other studies to infer what might be specific to SM policies in MIs and what general characteristics were observed across different sectors.

Another delimitation we need to acknowledge is as indicated above, national MIs often fall under governmental purview. In certain cases, broader policy instruments (e.g. governmental 


\begin{tabular}{|c|c|c|c|c|c|c|c|c|}
\hline 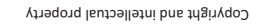 & $x$ & $x$ & $\mathrm{x}$ & $\mathrm{x}$ & $\mathrm{x}$ & & & $x$ \\
\hline иоب̣em. & $\mathrm{x}$ & & & & & & & $\mathrm{x}$ \\
\hline 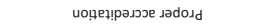 & $x$ & & & & $x$ & & & $x$ \\
\hline 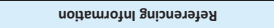 & $\mathrm{x}$ & $x$ & $x$ & $\mathrm{x}$ & $\mathrm{x}$ & & & $x$ \\
\hline 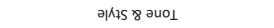 & $\mathrm{x}$ & $x$ & & $\mathrm{x}$ & $\mathrm{x}$ & & & $\mathrm{x}$ \\
\hline 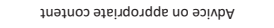 & $\mathrm{x}$ & $\mathrm{x}$ & $\mathrm{x}$ & & & & & \\
\hline 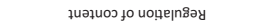 & $\mathrm{x}$ & & & $\mathrm{x}$ & $\mathrm{x}$ & & $x$ & $x$ \\
\hline 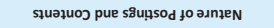 & $\mathrm{x}$ & $\mathrm{x}$ & $x$ & $\mathrm{x}$ & $\mathrm{x}$ & $x$ & $x$ & $x$ \\
\hline 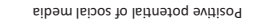 & $\mathrm{x}$ & & & $\mathrm{x}$ & & $\mathrm{x}$ & & \\
\hline ұиәшәәиечиә риеля & $\mathrm{x}$ & $x$ & $x$ & $\mathrm{x}$ & $x$ & & $x$ & $x$ \\
\hline adous & $\mathrm{x}$ & $x$ & $\mathrm{x}$ & $\mathrm{x}$ & $\mathrm{x}$ & & $x$ & $x$ \\
\hline әsn e!̣рәu ןẹวos Su!̣uyəa & $\mathrm{x}$ & $\mathrm{x}$ & $x$ & $x$ & $\mathrm{x}$ & $\mathrm{x}$ & $x$ & $x$ \\
\hline Кગ!|lod fo asod.And & $\mathrm{x}$ & $\mathrm{x}$ & $\mathrm{x}$ & $\mathrm{x}$ & $\mathrm{x}$ & $\mathrm{x}$ & $\mathrm{x}$ & $\mathrm{x}$ \\
\hline 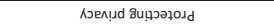 & & $\mathrm{x}$ & $\mathrm{x}$ & $\mathrm{x}$ & $\mathrm{x}$ & & & $\mathrm{x}$ \\
\hline 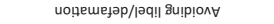 & $\mathrm{x}$ & $\mathrm{x}$ & $\mathrm{x}$ & $\mathrm{x}$ & & & & $\mathrm{x}$ \\
\hline иоџฺешлоли fо шорәәды & $x$ & & & $\mathrm{x}$ & & & & \\
\hline suop̣eגap!suoว |е8ిว & $\mathrm{x}$ & $\mathrm{x}$ & $\mathrm{x}$ & $\mathrm{x}$ & $\mathrm{x}$ & & & $\mathrm{x}$ \\
\hline 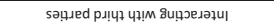 & & $\mathrm{x}$ & & $\mathrm{x}$ & & & $\mathrm{x}$ & $\mathrm{x}$ \\
\hline 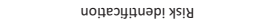 & & & $x$ & $\mathrm{x}$ & $x$ & & & \\
\hline 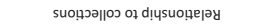 & $\mathrm{x}$ & $\mathrm{x}$ & $\mathrm{x}$ & & $\mathrm{x}$ & & $\mathrm{x}$ & $\mathrm{x}$ \\
\hline |еэب̣||ode 8uाu|̣eməy & $\mathrm{x}$ & $\mathrm{x}$ & $\mathrm{x}$ & $\mathrm{x}$ & & & & $\mathrm{x}$ \\
\hline 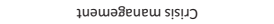 & $\mathrm{x}$ & & $\mathrm{x}$ & & & & & \\
\hline 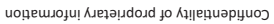 & $\mathrm{x}$ & $\mathrm{x}$ & $\mathrm{x}$ & $\mathrm{x}$ & $\mathrm{x}$ & & $\mathrm{x}$ & $\mathrm{x}$ \\
\hline 7иәшәรిеuеш иоцุęndəy & & & $\mathrm{x}$ & $\mathrm{x}$ & & $\mathrm{x}$ & $\mathrm{x}$ & $\mathrm{x}$ \\
\hline 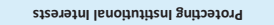 & $\mathrm{x}$ & $\mathrm{x}$ & $\mathrm{x}$ & $\mathrm{x}$ & $\mathrm{x}$ & $\mathrm{x}$ & $\mathrm{x}$ & $\mathrm{x}$ \\
\hline ҮАом ұе е!рәш ןејоо su!s ก & & & $\mathrm{x}$ & & $\mathrm{x}$ & $\mathrm{x}$ & $\mathrm{x}$ & \\
\hline גәш!̣|рs!़ ${ }_{n}$ имо Кш sмә! $\Lambda_{n}$ & $\mathrm{x}$ & & $\mathrm{x}$ & $\mathrm{x}$ & & $\mathrm{x}$ & $\mathrm{x}$ & $x$ \\
\hline 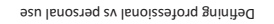 & $\mathrm{x}$ & $\mathrm{x}$ & $x$ & $\mathrm{x}$ & & $\mathrm{x}$ & $\mathrm{x}$ & $x$ \\
\hline asn 10y səןny & $x$ & $x$ & $x$ & $\mathrm{x}$ & $x$ & $x$ & $x$ & $x$ \\
\hline suoụ!̣əduos 8ụuuny & & & & & $\mathrm{x}$ & & & $x$ \\
\hline 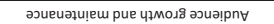 & & & & $\mathrm{x}$ & $\mathrm{x}$ & $\mathrm{x}$ & & $x$ \\
\hline иоцерләрош ұиәұиоэ & & & & & & & $\mathrm{x}$ & $x$ \\
\hline suодұеd чұ!м รищฺวедәңи & $\mathrm{x}$ & & $x$ & $\mathrm{x}$ & & $\mathrm{x}$ & & $\mathrm{x}$ \\
\hline 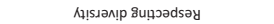 & $\mathrm{x}$ & & $x$ & & & & & \\
\hline 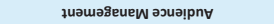 & $\mathrm{x}$ & & $\mathrm{x}$ & $\mathrm{x}$ & $\mathrm{x}$ & $\mathrm{x}$ & $\mathrm{x}$ & $x$ \\
\hline swлодерд рәлодdd $\forall$ & & $\mathrm{x}$ & & $\mathrm{x}$ & & $\mathrm{x}$ & $\mathrm{x}$ & $x$ \\
\hline 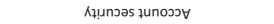 & & $\mathrm{x}$ & & & $\mathrm{x}$ & & $x$ & \\
\hline 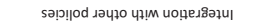 & $\mathrm{x}$ & $x$ & $x$ & $\mathrm{x}$ & $\mathrm{x}$ & & $\mathrm{x}$ & $x$ \\
\hline uоụen|елэ & $\mathrm{x}$ & $x$ & & $\mathrm{x}$ & $x$ & & & $x$ \\
\hline Кรวłеגłs pue suluue|d & & $\mathrm{x}$ & & $\mathrm{x}$ & $\mathrm{x}$ & $\mathrm{x}$ & & $\mathrm{x}$ \\
\hline 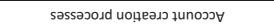 & $\mathrm{x}$ & $\mathrm{x}$ & & $\mathrm{x}$ & & & $\mathrm{x}$ & $x$ \\
\hline 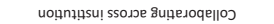 & $\mathrm{x}$ & $x$ & & & & & $\mathrm{x}$ & $x$ \\
\hline 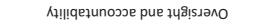 & $\mathrm{x}$ & $\mathrm{x}$ & $\mathrm{x}$ & $\mathrm{x}$ & $\mathrm{x}$ & $x$ & $\mathrm{x}$ & $\mathrm{x}$ \\
\hline \multirow[t]{2}{*}{ 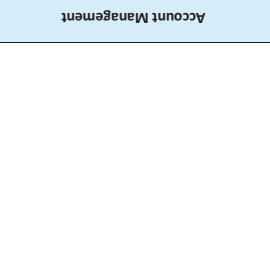 } & $x$ & $x$ & $x$ & $x$ & $x$ & $x$ & $x$ & $x$ \\
\hline & 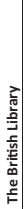 & 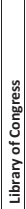 & 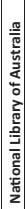 & 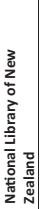 & 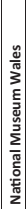 & 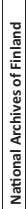 & 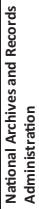 & 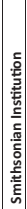 \\
\hline
\end{tabular}

National MIs SM policies and risk management

Table 1. Categories of themes and MIs 
communications policies and codes of conduct) may come to be the de facto SM guidelines or policies for these MIs. Examination of such broader instruments, unless referred to in the SM policies of the MI concerned, was beyond the scope of the current study. Follow-up studies could investigate these nested policy structures and their influence on SMRM in MIs.

\section{Findings}

A process of open and axial coding (Strauss and Corbin, 2008) produced 8 main categories and 36 sub-categories (Table 1). The main categories are as follows:

(1) Account management: The management of SM accounts. How are they established, monitored and evaluated? Who has authority over them? What is the chain of overseeing?

(2) Audience management: Scoping and interacting with audiences/communities on SM, and tailoring content to their interests.

(3) Rules for use: Regulations around staff use of SM, both at work and in personal capacity.

(4) Protecting institutional interests: Protection of the interests and integrity of the institution.

(5) Legal considerations: Advice on potential legal risks and legal compliance.

(6) Purpose of Policy: Outline of the intention of the policy itself.

(7) Nature of Postings and Content: Advice on what to post/not to post.

(8) Referencing Information: Advice/instructions to ensure correct referencing of thirdparty content posted on SM.

A document with explanation of how each theme and sub-category is defined along with example extracts from the policies is available from the corresponding author.

\subsection{General discussion}

From the content analysis, we can begin to draw some inferences about the risks that national MIs perceive with regard to SM use. In three instances, a number of risks were identified explicitly as part of a risk register, and thereby embedding risk identification and risk management into the policy. These institutions were the NLNZ, the National Library of Australia (NLA) and National Museum Wales (NMW). The NLNZ and NMW also included instructions on how to respond to and/or mitigate risks identified in the risk register. The former provided particularly comprehensive instructions and advice on risk mitigation. It is noteworthy that this policy is also applicable to other institutions across the NZ Department of Internal Affairs. As such, it is likely that effort has been invested into its comprehensiveness to cover the many and various activities and perceived risks of the Department's SM platforms.

In general, there are similarities between the policies of the institutions analysed and the findings of analyses of policies in other sectors. This was to be expected. The recognition of potential reputational damage is ubiquitous throughout the SMRM literature, and it was relatively common in the policies analysed in this research. Interestingly though, this was not universal. This is discussed in more depth under the sub-section below.

The categories developed from this content analysis bear a number of similarities to the themes identified by Pomerantz et al. (2015). These include those concerned with copyright issues, legal issues, advice on content and tone, provisos on personal use and the integration 
of the SM policy with other policies. Many of the legal issues Sherer et al. (2019) identified such as potential defamation/libel, threatening behaviour and the intentional or accidental potential sharing of private or confidential information were also evident in this study.

Defining and delineating personal and professional use was also a common theme. Previous studies have identified internal staff use as a risk. Sherer et al. (2019) and Haynes (2016) identified internal risks as more common and more risky than external risks. Some personal use-based risks, in addition to libel and inappropriate conduct on SM discussed by them include time wasting, data insecurity, fraud and copyright violation. This makes the need to provide some guidance as to how personal use of SM differs from professional use. This includes the level of use while on work hours, what kinds of situations might constitute speaking on behalf of the institution when commenting online in a personal capacity, and how to distance oneself from ostensibly making comments on behalf of the institution.

This kind of content was common in the policies we examined, consistent with the findings of Banghart et al. (2018). They investigated the ways in which corporate SM policies defined and regulated the boundaries between personal and professional SM use. This was through the framework of "boundaries" between personal and professional lives. They suggest that in the digital age, corporations are increasingly encroaching on the private lives of employees and that their SM policies serve to illustrate this. Over $75 \%$ of the 112 SM policies they analysed featured an articulation of the boundaries between personal and professional SM use. Many of these were "invasive" policies, which require employees to observe the SM policy in whole or in part when posting on SM even in a private capacity. They reach the conclusion that "these organizations are not simply regulating boundaries but colonising personal and public spheres by treating the entire online environment as an extension of the corporate sphere" (p. 362).

The SM policies examined in our study suggest similar encroachment upon personal and private lives, albeit with varying extent. For example, the British Library (BL) provides relatively comprehensive instructions about what is considered personal and professional use. This reduces ambiguity. As an example, they provide the general guidance that when posts relate "specifically or predominantly about issues related to your role at the British Library, then this may be considered official use". They also include the statement that employees are not expected to respond to or update official SM outside of work hours unless their job description specifically obliges them to. In this way, the BL provides its employees a clear sense of what counts as "official" use and therefore falls within the policy, while respecting their right to use SM privately and/or distance themselves from SM while off the clock. The NLA by contrast has a relatively more "invasive" stance on the matter, advising employees that "participating in private SM must uphold the APS Values and Code of Conduct even when material is posted anonymously, or using an 'alias' or pseudonym. They should bear in mind that even if they do not identify themselves online as an APS employee or an employee of their agency, they could nonetheless be recognised as such as SM website are public forums". It is debatable whether this is a reasonable or enforceable level of control over private SM use.

This finding indicates that at least in a formal sense, the boundaries between personal and professional use of SM can be blurry, and as such pose a reputational risk to MIs. The SM policies we analysed provide different examples of mitigating this type of risk, while respecting the right of their employees to behave as private citizens online. Holding these two imperatives in tension poses an ethical question for MIs and perhaps, other organisations with SM policies. One common strategy to attempt to diffuse some of this tensions found in our sample was through the suggestion that employees provide a disclaimer, either in a personal profile or in an individual message, identifying that they were an employee of a particular institution but were not presenting official opinion in their personal SM use. Six of the policies analysed contained such a suggestion. This strategy could be considered in the policy development and implementations for other MIs, should this aspect of SM use is a concern for them.
National MIs SM policies and risk management 
Other common features relate to providing definitions of SM within the policy, advising readers the scope of the policy, i.e. what it encompasses, who it applies to and the processes of account management. There are elements in our sample that appear to be particular to MIs. The following sub-sections unpack our findings in more detail, offering some thoughts on how they relate to the context of MIs.

\subsection{Reputational management and institutional interests}

Five of the policies analysed contained content advising staff that SM use holds risks to reputation damage of the institution. The NLA and the BL contained procedures for managing communication crises that might arise from the use of SM or directives to refer negative comments on SM to communications and customer service departments. This instruction, though contained to only these two institutions, demonstrates the stakes of potential reputational damage caused by crises such as, for example, that experienced by the MFA (Liverant, 2017). To offload particularly difficult situations to professional communications advisors rather than allow other employees to handle it and potentially do more damage indicates how serious MIs perceive this risk to be.

Overall, it appears that as suggested in previous research (Liew et al., 2018), potential reputational damage was a risk explicitly noted by most of national MIs and as such, should be addressed in their SM policies.

An interesting observation from our study sample was that more common than statements about protecting institutional reputation were statements that advised staff to avoid accidently or intentionally using SM to reveal confidential and/or proprietary information relating to the institution. Of those policies, seven contained such statements. The Smithsonian Institution (SI) for instance includes the statement that content " must not be posted that is confidential, proprietary, pre-decisional, internal or otherwise not intended for public dissemination", while the NLA notes that staff "should not comment in depth on the activities of another Branch or Division of the Library apart from providing factual information that is on the public record, unless employees have authority to do so". These examples suggest there is a perceived risk that staff might intentionally or not, leak information relating to commercially or professionally sensitive information or processes used by the institution that requires protection to maintain their integrity. This might presumably include an exhibition under development or culturally sensitive collection items.

NMW provides another interesting example related to this type of risk. Its SM policies instruct that "Users must not include images of back-of house that show corridors or windows in context, door numbers nor the precise location of any objects". This frames this risk around potential security threats to the collections. Given the cultural and financial value of many items in these institutions' collections, content that provides would-be thieves or vandals with information about the security measures in place at the museum could compromise those same measures.

\subsection{Legal considerations}

It is not surprising that concerns regarding copyright and appropriate accreditation are commonly reflected in the policies of the national collecting institutions. Not only there is a legal mandate behind this, but there is also a professional motivation (Deazley and Wallace, 2017). How can MIs expect users and the public to respect the provenance, copyright and reference information of items in their collections if they do not do so themselves on SM? While the need to respect intellectual rights and copyright is not unique to MIs, the expectation to have users respect the provenance of their collection items make this a particularly relevant concern for MIs and should be aptly addressed in their SM policies. 


\subsection{Apolitical stance}

Another interesting finding is the frequency of directives instructing the SM presence of a particular institution to be apolitical or bipartisan. Of those analysed policies, five policies featured such content. Such directives explicitly prohibit the posting of any messaging that might explicitly or implicitly endorse a particular political party or political movement. As a typical example, the SI's policy states that "Political or religious messages or endorsements of political parties, candidates or groups or comments that might be construed as lobbying must not be posted". As instruments of governments, it makes sense that national MIs would include such directives. They are part of the framework of official record-keeping and cultural communication. Like most other elements of public services, their independence from the politics of electoral democracy is deemed an important part of their foundation.

It would be interesting to compare this to the policies from other institutions that are smaller or more tightly focused. Might a small community archive or library, for example, be more inclined to advocate for a particular political position or civic movement via their SM? Would this be reflected in their SM policy, either by the explicit permission of such activity or by the absence of a statement requiring an apolitical stance? These are the questions to be explored in future research. A comparison between SM policies of national-level MIs and community-driven or specialised MIs might reveal some differences in how they approach political discourses.

This could also be integrated into a broader discussion of the contemporary politics of collective memories and cultural heritage. While traditionally, in view of their professional ethics, MIs have tended towards an apolitical stance, scholars are now arguing for a need for MIs to be explicitly political in some instances, to use their collections and their expertise to advocate on behalf of the marginalised and to address systemic injustices (Caswell, 2014; Flinn et al., 2009). These scholars argue that national-level MIs are inherently political anyway by what they have historically chosen to collect and preserve and what they prioritise in their curation. The decisions these institutions make about whose history they preserve and communicate and how those memory records are represented and organised in their collections have not necessarily been apolitical. While institutions such as national libraries and national archives might conventionally discouraged the endorsement of certain political stances, do these institutions have an increasingly important responsibility to the diverse communities they purport to represent through their curation? Might this require MIs to use their collections and expertise to support civic movements that promote social inclusiveness and social cohesion (Liew and Cheetham, 2016) and take a stance against the continuation or promotion of discrimination/biases against certain groups/communities though their SM platforms, when necessary? These are aspects noteworthy of consideration in policy formulation or further iterations of policies in MIs.

\subsection{Management and accountability}

All the policies that were analysed contained statements indicating the positive value and opportunities afforded by SM to enhance the brand, goals and mission of the institution. Likewise, all the policies also carried information that warned against or prohibited particular activities or postings. How this balance between SM as a beneficial opportunity and as a risk was framed differently across the sample. Some were far more restrictive, suggesting a more risk-averse approach. Others played up the positives to a greater degree.

This difference was particularly evident in statements with regard to account management. Some policies laid out very rigorous hierarchies which mandated sign-offs and approval at multiple stages. Others deployed more of a "you know best" approach that entrusts staff to behave responsibly and within the general remit of the SM policy, with looser, though not entirely absent procedures for oversight and accountability. The former approach signals a 
more risk-averse approach, in which SM activities must have multiple levels of oversight and accountability. The SI for example expends three of its twelve pages of policy document identifying the different offices and individuals who have a role in approving, planning and providing oversight over SM use. The Library of Congress (LC), likewise an institution of the Federal Government of the USA, requires sign-off from many of the same governmental offices. It also requires that communications plans be submitted for every new SM initiatives. These policies place a fairly substantial amount of red-tape around SM use. Whether this restricts SM use in practice would require insights from those involved in these institutions. Nevertheless, the nature of these policy statements implies a relatively risk-averse approach to SM governance.

By contrast, other policies layout a method of SM governance that takes a less stringent approach. The BL's policy for instance, emphasises that the points contained in the policy "are not designed to discourage you from setting up or using SM accounts" and asks that staff speak with the communications team if they have any questions about appropriate conduct. They also provide links to what constitutes "good" use of SM that provides an example to aspire. This signals that they want staff to take advantage of the benefits that SM affords, but to do so within a guided environment. The NLNZ's policy document is even more emphatic in its endorsement of trusting staff, noting that nothing "kills the effectiveness of a SM project than slow response times where each and every statement or 'tweet' needs to go up the chain of command to be approved before publication". The message conveyed was that the risks their policy identifies are not intended to inhibit SM use but to provide examples of situations to avoid.

To what extent these broad, different approaches inhibit or facilitate effective, creative use of SM would require an in-depth examination of the actual SM postings and activities of these institutions. Nevertheless, it appears that there are different philosophies and approaches to these basic elements, which in turn seem to suggest different risk tolerance levels among the MIs. Institutions developing and revising their SM policies should consider which approach characterises their stance on SM use in a better way, in line with their broader mission. This does not however, need to be set up as a binary "stringent" vs "lenient" SM policy debate. It might be more constructive to view this on a spectrum. Some aspects of institutional SM use may benefit from a more relaxed set of guidelines while other aspects may call for a more guarded set of rules.

Most policies also placed an emphasis on planning with regard to SM use, including advice/statements about identifying and growing target audience, ensuring contents are produced and posted regularly and setting goals for what to accomplish from the SM use. Cadell (2013) argues that part of the value of SM policies is to provide staff with a framework around which to plan and execute SM use. In this sense, having these directives to be intentional in SM use and, to plan for SM contents and activities could be helpful in encouraging meaningful SM use.

\subsection{References to collections and collections management}

In general, the policies examined are relatively light on content that relates the use of SM directly to institutional philosophies of collection management. A few mentioned the preservation of institutional SM for posterity, thereby integrating the MI's SM into its broader collection policy. There is a growing imperative for MIs to archive SM content (Macnaught, 2018; Sheffield, 2018; Velte, 2018). As such, these kinds of policies should be a part of this development within the memory sector, including statements about intentions and priorities for SM collecting, scope and provenance. MIs should be wary that biases of inclusion/ exclusion are not "introduced" or amplified in their decisions around SM content collecting. Given the complexity of preserving social web contents, it would be useful for such policies to 
include an outline, at least for internal references, of potential technological and curatorial challenges that should be taken heed of (e.g. the dynamic, ephemeral and unstable nature of social web and dependencies on third-parties), as well as potential legal and ethical issues (e.g. data ownership and potentially sensitive information).

There were also instances in which staff were advised on how to relate collections content on SM to digital content hosted on the institution's own website. The LC for example, instructs that "Collections content uploaded to non-Library hosted SM platform must also be available on a Libraryhosted website, unless explicit exception has been granted". In a similar vein, the BL advises that staff "should be aware that the Library asserts intellectual property rights in its own digitised content ... there may be some content (for example high resolution images sold by Imaging Services...) that is not appropriate for sharing on social media platforms". These examples suggest something about the stance on using SM to share contents from collections. $\mathrm{SM}$ is by no means meant to replace, in whole or in part, the digital collections. It might be a way to raise awareness of institutional collections and to encourage them to explore the collections. This ties in with the frequent presence of content (seven of the eight policies) that indicate that $\mathrm{SM}$ is meant to enhance the brand/goals/mission of the institution, which is a common feature noted in previous SM policy research (McNeill, 2012; Cadell, 2013). SM is perceived as a means to communicate the value of the collections and not as a stand-in for the services the institutions offer.

\subsection{Links to participatory cultural heritage practices}

Content analyses of SM policies in the government and media sectors suggest that they have not embraced the potential for greater audience/citizen interaction that is increasingly becoming a part of how consumers of news and citizens are engaging with these institutions (Lee, 2016; Klang and Nolin, 2011; Bennett and Manoharan, 2017). With the rise of participatory cultural heritage projects via digital platforms (Liew et al., 2020; Burkey, 2019), those working in and researching MIs are facing similar questions about how to meaningful collaborate with and incorporate the perspectives of audiences into their practice (Liew, 2016; Parilla and Ferriter, 2016; Stein, 2012).

Is this emergent facet of collective memory curation reflected in the SM policies? In general, there are statements on using appropriate tone and conduct when communicating and interacting with patrons, advice on how to moderate comments and postings made by users to ensure offensive or inappropriate contents are avoided/censored from their SM platforms. Some policies also featured advice on how to identify, develop and maintain an audience and how to tailor content to that audience's preferences. While this indicates some willingness to go with the audience on their preferences, this is not the same as actively inviting them into the process of co-creating, collecting, describing and curating cultural heritage. There is little to suggest in our findings that ideas of participatory cultural heritage has been reflected in or has informed the MIs' SM policies.

The National Archives of Finland observes that a benefit of using SM is that staff can "share information about your work as an expert, cut down rumours and correct misunderstandings or erroneous information". While correcting falsehoods is self-evidently valuable for the institution's interests, it suggests a one-way flow of communication. It does also suggest that SM lets staff "learn more about the operations and thoughts of your stakeholders". While this does encourage some kind of discourse between staff and stakeholders via SM, the overall impression is one of staff using SM as a means to share their expertise, rather than collaborate with stakeholders. This does not necessarily mean that these MIs are not engaged in meaningful participatory practices elsewhere in their operations, only that it does not appear to have informed SM policies to any significant degree. This may suggest that these MIs have not 
fully grasped the potential for SM to be a platform for greater stakeholder engagement as a core function. Further research into actual practices would be necessary to comprehend this further.

\section{Conclusion and avenues for further research}

This research contributes insights into how national MIs frame the opportunities and the risks of SM use, the ways in which they govern usage of SM and their different approaches to SMRM. National-level MIs perceive many similar risks but their framing of and addressing of these risks vary. Institutions such as the NLNZ and the BL seem to place more emphasis on the benefits of SM use, providing a looser leash for employees to trust themselves to use the media in innovative ways. Others appear to be more risk-averse in the way they establish their governance systems, with many checks and balances. A larger sample and a comparison with MIs with different mandates and priorities would provide further points of comparison with the current findings. This could reveal other perspectives not captured in our relatively small sample. Further research in this area would help to build a broader picture of how MIs formulate their SM policies, in response to how risk is framed. As stated, it would also be worthwhile investigating any nested policy structures and broader governmental policy instruments, and their influence on SMRM in national MIs.

In follow-up studies, it would also be valuable to include a wider sample that includes not only national institutions but also municipal/local institutions, community-driven institutions and institutions that operates in a digital sphere (e.g. https:/www.europeana.eu). A more expansive study could reveal a spectrum of approaches to SMRM in the memory sector. Do institutions that do not have a national mandate frame their SM use and practices differently? Are they less riskaverse? Do they place different emphases on different kinds of risks or outcomes? If so, what are some of the inferences we might make to explain these differences? Such examinations could lead to insights into more nuanced details communicated in the policies reflecting SM use and practices of different types of MIs with different mandates and priorities.

It would also be worthwhile comparing the current analysis with empirical elements of SM use and activities that can be captured through their SM platforms. This could for instance, involve a comprehensive analysis of SM postings and activities, comparing it to the SM policy of the MI concerned and exploring how practical use relates and compares to prescribed guidelines. This could be supplemented by interviewing or surveying professionals in the MIs with regard to their attitudes and actual SM use practices.

A couple of additional points worthy of note for further discussion emerge from the findings, with regard to the extent SM policies reflect contemporary discourses within the memory sector. There is little in our findings to suggest that emerging participatory cultural heritage practices within the memory sector have been methodically reflected in SM policies. Directives to remain apolitical may reflect long-established statutory requirements to impartiality, but the supposed neutrality of MIs has come under scrutiny. These are areas imploring investigations. It is necessary for MIs to acknowledge the broader context and dialogues currently underway in the cultural heritage sector, and on the potential use of SM by MIs in contributing to discourses on contemporary concerns and on addressing power structures and normativity of MIs. This calls for a scrutiny of the potentially complex roles $\mathrm{SM}$ policies have in MIs in relation to their public/civic mandates.

\section{References}

Banghart, S., Etter, M. and Stohl, C. (2018), "Organizational boundary regulation through social media policies", Management Communication Quarterly, Vol. 32 No. 3, pp. 337-373.

Bennett, L.V. and Manoharan, A.P. (2017), "The Use of social media by US municipalities", International Journal of Public Administration, Vol. 40 No. 4, pp. 317-328. 
Bertot, J.C., Jaeger, P.T. and Hansen, D. (2012), "The impact of policies on government social media usage: issues, challenges, and recommendations", Government Information Quarterly, Vol. 29, pp. $30-40$.

Burkey, B. (2019), "Total recall: how cultural heritage communities use digital initiatives and platforms for collective remembering", Journal of Creative Communications, Vol. 14 No. 3, pp. 235-253.

Cadell, L. (2013), "Socially practical or practically unsociable? A study into the social media policy experiences in Queensland cultural heritage institutions", Australian Academic and Research Libraries, Vol. 44 No. 1, pp. 3-13.

Caswell, M. (2014), "Seeing yourself in history: community archives and the fight against symbolic annihilation", The Public Historian, Vol. 36 No. 4, pp. 26-37.

Cole-Miller, K., Ward, W., Fruhling, A. and Cooper, K.D. (2016), "Social media policies in the Department of Defense: do they address the risk?", Journal of Information Privacy and Security, Vol. 12 No. 2, pp. 93-102.

Comrie, E.L., Burns, C., Coulson, A.B., Quigley, J. and Quigley, K.F. (2019), "Rationalising the use of Twitter by official organisations during risk events: operationalising the social amplification of risk framework through causal loop diagrams", European Journal of Operational Research, Vol. 272 No. 2, pp. 792-801.

Deazley, R. and Wallace, A. (2017), "Copyright and cultural memory”, CREATe Working Paper Series, doi: 10.5281/zenodo.345968.

Demek, K.C., Raschke, R.L., Janvrin, D.J. and Dilla, W.N. (2018), "Do organizations use a formalized risk management process to address social media risk?", International Journal of Accounting Information Systems, Vol. 28, pp. 31-44.

Di Gangi, P.M., Johnston, A.C., Worrell, J.L. and Thompson, S.C. (2018), "What could possibly go wrong? A multi-panel Delphi study of organizational social media risk", Information Systems Frontiers, Vol. 10, pp. 1097-1116.

Duff, W., Johnson, C.A. and Cherry, J.M. (2013), "Reaching out, reaching in: a preliminary investigation into archives' use of social media in Canada", Archivaria, Vol. 75 April, pp. 77-96.

Duffy, A. and Knight, M. (2019), "Don't be stupid: the role of social media policies in journalistic boundary-setting”, Journalism Studies, Vol. 20 No. 7, pp. 932-951.

Faber, B., Budding, T. and Gradus, R. (2020), "Assessing social media use in Dutch municipalities: political, institutional and socio-economic determinants", Government Information Quarterly, Vol. 37, doi: 10.1016/j.giq.2020.101484.

Fleming, R. and Damala, A. (2016), "Finding the voice: planning and evaluation of social media in cultural institutions", Presented at MW2016: Museums and the Web 2016.

Fletcher, A. and Lee, M. (2012), "Current social media uses and evaluations in American museums", Museum Management and Curatorship, Vol. 27, pp. 505-521.

Flinn, A., Stevens, M. and Shepherd, E. (2009), "Whose memories, whose archives? Independent community archives, autonomy and the mainstream”, Archival Science, Vol. 9, pp. 71-86.

Fudurić, M. and Mandelli, A. (2017), "Corporate and non-profit social media policies: a content analysis”, Market-Tržišste, Vol. 27 No. 1, pp. 7-22.

Haynes, D. (2016), "Social media, risk and information governance", Business Information Review, Vol. 33 No. 2, pp. 90-93.

Heyliger, S., McLoone, J. and Thomas, N. (2013), “Making connections: a survey of special collections' social media outreach", American Archivist, Vol. 76 No. 2, pp. 374-414.

Hrdinová, J., Helbig, N. and Peters, C.S. (2010), Designing Social Media Policy for Government: Eight Essential Elements, Center for Technology in Government, Washington, DC, available at: https://www.brookings.edu/wp-content/uploads/2016/06/01_social_media_policy.pdf.

Klang, M. and Nolin, J. (2011), "Disciplining social media: an analysis of social media policies in 26 Swedish municipalities", First Monday, Vol. 16 No. 8.
National MIs SM policies and risk management 
Köseoğlu, Ö. and Tuncer, A. (2016), "Designing social media policy for local governments: opportunities and challenges", in Sobaci, M.Z. (Ed.), Social Media and Local Governments: Theory and Practice, Springer, Cham, pp. 22-36.

Lee, J. (2016), "Opportunity or risk? How news organizations frame social media in their guidelines for journalists", The Communication Review, Vol. 19 No. 2, pp. 106-127.

Lessard, B.D., Whiffin, A.L. and Wild, A.L. (2017), "A guide to public engagement for entomological collections and natural history museums in the age of social media", Annals of the Entomological Society of America, Vol. 110 No. 5, pp. 467-479.

Liew, C.L. (2016), "Social metadata and public-contributed contents in memory institutions: "crowd voice' vs 'authenticated heritage'?", Preservation, Digital Technology and Culture, Vol. 45 No. 3, pp. 122-133.

Liew, C.L. and Cheetham, F. (2016), "Participatory culture in memory institutions: of diversity, ethics and trust?", D-lib Magazine, Vol. 22 No 7/8.

Liew, C.L., Oliver, G. and Watkins, M. (2018), "Insight from social media use by memory institutions in New Zealand: participatory vs curatorial culture”, Online Information Review, Vol. 42 No. 1, pp. 93-106.

Liew, C.L., Goulding, A. and Nichols, M. (2020), "From shoeboxes to shared spaces: participatory cultural heritage via digital platforms", Information, Communication and Society. doi: 10.1080/ 1369118X.2020.1851391.

Liverant, N.U. (2017), "Tweet carefully, museums: a case study of the \#decolonizeourmuseums protest”, (Unpublished Master's Thesis), Victoria University of Wellington.

Macnaught, B. (2018), "Social media collecting at the national library of New Zealand", available at: http://library.ifla.org/2274/1/093-macnaught-en.pdf.

Magoi, J.S., Aspura, M.K.Y.I. and Abrizah, A. (2019), "Social media engagement in developing countries: boon or bane for academic libraries?", Information Development, Vol. 35 No. 3, pp. 374-387.

Manžuch, Z. (2009), “Archives, libraries and museums as communicators of memory in the European Union projects", Information Research, Vol. 14 No. 2.

Mathur, M. (2019), "Where is the security blanket? Developing social media marketing capability as a shield from perceived cybersecurity risk", Journal of Promotion Management, Vol. 25 No. 2, pp. 200-224.

McNeill, T. (2012), “'Don't affect the share price': social media policy in higher education as reputation management", Research in Learning Technology, Vol. 20, pp. 152-162.

Miller, L.A. (2018), "Social media savvy: risk versus benefit", Journal of Perinatal and Neonatal Nursing, Vol. 32 No. 3, pp. 206-208.

Parilla, L. and Ferriter, M. (2016), "Social media and crowdsourced transcription of historical materials at the Smithsonian Institution: methods for strengthening community engagement and its tie to transcription output", American Archivist, Vol. 79 No. 2, pp. 438-460.

Pasquini, L.A. and Evangelopoulos, N. (2017), "Sociotechnical stewardship in high education: a field study of social media policy documents", Journal of Computing in Higher Education, Vol. 29 No. 2, pp. 218-239.

Pomerantz, J., Hank, C. and Sugimoto, C.R. (2015), "The state of social media policies in higher education", Plos One, Vol. 10 No. 5.

Rodesiler, L. (2017), "Local social media policies governing teachers' professionally oriented participation online: a content analysis", TechTrends, Vol. 61, pp. 293-300.

Ryan, G. (2016), "International perspectives on social media guidance for nurses: a content analysis", Nursing Management, Vol. 23 No. 8, pp. 28-35.

Sheffield, R.T. (2018), "Facebook Live as a recordmaking technology", Archivaria, Vol. 85 May, pp. $96-121$. 
Sherer, J.A., McLellan, M.L. and Yantis, B.A. (2019), "The (social) media is the message: navigating legal and reputational risks associated with employee social media use", Computer and Internet Lawyer, Vol. 36 No. 5, pp. 1-7.

Stein, R. (2012), "Chiming in on museums and participatory culture", Curator: The Museum Journal, Vol. 55 No. 2, pp. 215-226.

National MIs

SM policies

and risk

management

Strauss, A.L. and Corbin, J.M. (2008), Basics of Qualitative Research: Grounded Theory Procedures and Techniques, 3rd ed., Sage, Thousand Oaks, CA.

Velte, A. (2018), "Ethical challenges and current practices in activist social media archives", American Archivist, Vol. 81 No. 1, pp. 112-134.

Walsh, J.P. and O'Connor, C. (2019), “Social media and policing: a review of recent research”, Sociology Compass, Vol. 13, No. 1.

Williamson, F., Vieira, S. and Williamson, J. (2015), "Marketing finding aids on social media: what worked and what didn't work", American Archivist, Vol. 78 No. 2, pp. 488-513.

\section{Corresponding author}

Chern Li Liew can be contacted at: ChernLi.Liew@vuw.ac.nz

For instructions on how to order reprints of this article, please visit our website:

www.emeraldgrouppublishing.com/licensing/reprints.htm

Or contact us for further details: permissions@emeraldinsight.com 